\title{
SYNOPSIS
}

News

-

Analysis

Practice

Technological Change

\section{Declining CABG rate means fewer jobs for surgeons}

Increased rates of percutaneous coronary intervention (PCI) in Canada and the subsequent decrease in coronary artery bypass grafts (CABG) are decreasing the need for cardiac surgeons and shortening some provincial waiting times, report some experts.

The Canadian Institute for Health Information and Statistics Canada report a $2.8 \%$ decrease in CABG rates and a $66 \%$ increase in the number PCIs or angioplasties performed across Canada between 1998-99 and 2002-03.

The Ontario Institute for Clinical Evaluative Sciences (ICES) stated in Access to Health Service in Ontario (2005) that increased use of PCI relative to bypass surgery is chiefly due to the increased efficacy and declining price of stents, particularly drug-eluting stents.

The American Heart Association reports a similar trend south of the border. Between 1997 and 2002 the number of angioplasty and stent procedures increased 31\% (from 916000 to 1.2 million), while the number of CABG procedures decreased 15\% (from 607000 to 515000 ).

CABG rates are continuing to fall, says cardiologist Jack Tu, coauthor of the ICES report and team leader of the Canadian Cardiovascular Outcomes Research Team (CCORT). "Anecdotally, a lot of surgeons are concerned they don't have the [procedure] volume to meet their targets for [government] funding [as a cardiac centre]," says Tu, a senior scientist at ICES and Canada Research Chair in

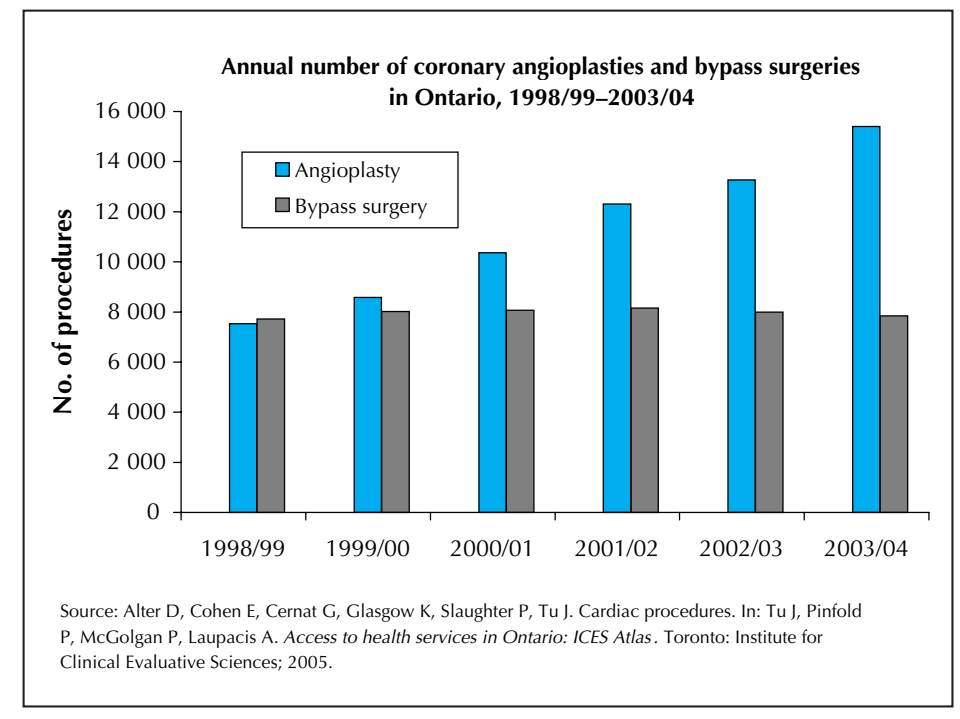

Health Services Research.

Volumes will "definitely" continue to fall, resulting, eventually, in a surplus of cardiac surgeons, says Tu. "We need to stop training so many. They're not going to have a lot of work."

Those residency spots should be filled by other cardiac specialists, such as cardiac electrophysiologists, he says.

That may be premature, says Edmonton cardiac surgeon Dr. David Ross, who sits on the Royal College of Physicians and Surgeons of Canada's Cardiac Surgery Specialty Committee. He cautions that forecasting human resource needs based on this decrease alone is difficult.

For example, other types of work may be increasing. In Alberta, the number of implanted defibrillators is doubling each year, Ross says.

Before adjusting residency numbers, there also needs to be a long-term demonstration of the efficacy of stents. "Until the true impact of stenting is known it's almost impossible to predict numbers," Ross said.

Forecasting is also difficult when there are only 140 cardiac surgeons in Canada. "If 5 retire, we have a shortage," says Ross.

In 2002 and 2003, only about half the expected number of physicians retired, according to the CMA. Numbers are rising again, which could result in jobs for new surgeons.

Ross also argues that the decrease in CABG procedures may be an opportunity to reduce cardiac surgeons' workloads. Cardiac surgeons spend more time in the operating room - typically 3 to 5 days a week - than other surgical specialists, who average 2 days a week, he says. "Maybe we can do other things, not just OR. More ICU for example.” 
The decrease in CABG rates does, however, "show the danger of a specialty relying on 1 operation," says Ross. And he admits that new graduates are having a "tough time finding work" in Canada and the US.

Dr. Stephen Fremes, head of cardiac surgery at Sunnybrook and Women's College Health Sciences Centre in Toronto estimates that 10 to 15 newly certified cardiac surgeons in Canada are currently without full-time work. Ten cardiac surgeons were certified this year. One of Fremes' trainees has a job lined up for next year but 3 others, including Dr. Fuad Moussa, are still seeking full-time positions.

Moussa says that as far as he knows there are no jobs in Canada for the country's 18 newly certified cardiac surgeons.
Moussa, who is currently working as a fellow at Sunnybrook, is considering, reluctantly, a move to another country. He started to get "alarmed" about the employment situation in his second year of training. Now, at 36, with 19 years of post-secondary education, a wife, 3-year-old child and \$30 000 in debt, he faces an uncertain future.

Fremes says training may need to change so cardiac surgeons can perform other surgeries, such as vascular.

He says replacing fee-forservice with salary is another option for increasing opportunities for young surgeons.

Meanwhile, another 14 cardiac surgeons are due to be certified in 2006 and 13 in 2007.

With the decrease in CABGs, there are also reports of shorter wait times in some provinces.

In Ontario there are virtually no wait times, reports Fremes. The most recent figures indicate that wait times for CABG after acute myocardial infarction (AMI) declined from 43 days (1997-2000) to 12 days (2001-02).

In Quebec, where the number of CABG procedures declined from 12031 in 1997 to 11621 in 2003, the median wait time from AMI to CABG declined $45.6 \%$ (from 33 days in 1997 to 18 days in 2002), reports Dr. Louise Pilote at McGill University in Montréal.

In Alberta, waiting lists for open heart surgery have plummeted in the past 5 years, from 450 cases and over a year wait, to 150 cases and a 6-week wait. Barbara Sibbald, CMAJ

\section{Physician SUPply}

\section{Canada and UK must stop taking African doctors}

Canada must become selfsufficient in physician supply by increasing residency positions, quadrupling re-entry positions and launching long-term, panCanadian planning, delegates to the Canadian Medical Association's General Council decided Aug. 17.

Currently, 24\% of Canadian physicians are international graduates.

Although international medical graduates can fill the human resource gap on a short-term basis, "[w]ealthy Canadians cannot and must not rely on the systematic recruitment of doctors from countries that cannot legitimately afford it," said Dr. Peter Barrett, a Saskatoon physician and former CMA president (2000).

Dr. Michael Wilks, Chair of the Representative Council of the British Medial Association (BMA), told delegates sub-Saharan Africa now needs 1 million new physicians, but is losing many to the UK and other developed nations.

"Self-sufficiency is critical to success. If we fail, we can't ad- dress the problem globally either," he told the Canadian delegates.

Nearly half of newly registered physicians and nurses in the UK were recruited from outside the European Union in 2002; most were from the English-speaking countries of subSaharan Africa (Lancet 2005;365: 1893-900)

"At the moment, richer countries simply aren't doing enough to prevent a complete catastrophe," said Dr. Edwin Borman, chairman of the BMA International Committee.

In 2003, the UK registered 5880 health and medical personnel from South Africa, 2825 from Zimbabwe, 1520 from Nigeria and 850 from Ghana. The UN Conference on Trade and Development estimates that each African professional migrant represents a loss of US\$184000 to Africa.

The UK has an ethics code preventing active recruitment from some developing regions, including sub-Saharan Africa, but allows doctors from these areas to apply for UK posts.

A May 11 report from the BMA and international partner organizations, including the CMA, found that "lives are being lost because of severe shortages of health care workers in areas such as sub-Saharan Africa, and that further losses of staff will cause the death toll to rise even further."

The impact of migration from developing to developed countries is a significant component in the crisis, the paper states. It calls for the UK and other countries to end their reliance on overseas doctors and nurses.

Curently, $31 \%$ of practising physicians and $13 \%$ of nurses were born outside the UK.

The World Medical Association recently reaffirmed its policy that "every country should do its utmost to educate an adequate number of physicians ... [and] not rely on immigration from other countries to meet its need for physicians." - Vittal Katikireddi, Edinburgh, Scotland 